\title{
Cognitive function and its associations in older adults from Amazonas, Brazil
}

\section{Função Cognitiva e suas associações em adultos-idosos do estado do Amazonas, Brasil}

\author{
AUTHOR'S \\ Maria Antonieta Tinôco ${ }^{10}$ (iD \\ Élvio Rúbio Gouveia $a^{2,3,4}$ (D) \\ Andreas Ihle ${ }^{1,2}$ (D) \\ Matthias Kliegel $1^{1,2}$ (D) \\ Jefferson Jurema ${ }^{8}$ (D) \\ Floramara Teles Machado ${ }^{8}$ (D) \\ Angeany Pinto Odim ${ }^{8}$ (D) \\ Bárbara Régia Muniz ${ }^{9}$ (D) \\ Euler Esteves Ribeiro ${ }^{11,12,13}$ (D) \\ Bruna Raquel Gouveia ${ }^{2,4,5,6}$ (D) \\ Duarte Luís Freitas ${ }^{3,7}$ (D) \\ 1 Department of Psychology, University of Geneva, \\ Geneva, Switzerland. \\ 2 Center for the Interdisciplinary Study of \\ Gerontology and Vulnerability, University of \\ Geneva, Geneva, Switzerland. \\ 3 Department of Physical Education and Sports, \\ University of Madeira, Funchal, Ilha da Madeira, \\ Portugal. \\ 4 Institute of Interactive Technology, University of \\ Madeira, Funchal, Ilha da Madeira, Portugal. \\ 5 School of Nursing, São José de Cluny, Funchal, \\ Ilha da Madeira, Portugal. \\ 6 Institute of Health Management and Social \\ Affairs, Funchal, Ilha da Madeira, Portugal. \\ 7 Department of Mathematical Sciences, University \\ of Essex, Colchester, United Kingdom. \\ 8 Department of Physical Education and Sports, \\ Amazonas State University, Manaus, Amazonas, \\ Brazil. \\ 9 Manaus City Hall - City Department of Youth, \\ Sports and Leisure, Manaus, Amazonas, Brazil. \\ 10 Federal Institute of Education, Science and \\ Technology, Amazonas, Manaus, Amazonas, Brazil. \\ 11 School of Medicine, Amazonas State University, \\ Manaus, Amazonas, Brazil. \\ 12 Open University for Senior Citizens, Amazonas \\ State University, Manaus, Amazonas, Brazil. \\ 13 School of Medicine, Pontifical Catholic \\ University, Porto Alegre, Rio Grande do Sul, Brazil.
}

\section{CORRESPONDING}

Maria Antonieta de Campos Tinôco nittin@me.com

Instituto Federal de Educação, Ciência e Tecnologia do Amazonas. Avenida Sete de Setembro, 1975, Centro, Manaus, Amazonas, Brasil. CEP: 69020-120.

DOI

$10.12820 /$ rbafs.23e0013

\begin{abstract}
The objectives of this study were: (1) to investigate the age-related differences in cognitive function $(\mathrm{CF})$, nutritional status (MNA), physical activity $(\mathrm{AF})$, quality of life (QoL), depression, social satisfaction (SS) and socioeconomic status (SES), and (2) to explore the relationships between CF and the previous variables. This cross sectional study included 268 men and 433 women (aged $71.4 \pm$ 7.0 years). CF was determined with the Cognitive Telephone Screening Instrument (COGTEL) and the Mini-Mental State Examination (MMSE). Correlates were as follows: Mini Nutritional Assessment (MNA), PA (Baecke questionnaire modified for older adults), Quality of life (QoL SF12), Geriatrics Depression Scale (GDS), Satisfaction and Social Support Scale, and Socioeconomic status (SES). All instruments were applied in a face to face interview. An independent t-test identified significantly higher scores in young-old adults ( $\leq 69$ years) for CF $(p<0.001), P A(p=0.046)$ and SES ( $p=0.007$ ), compared to old-old adults ( $\geq 70$ years). The results of multiple linear regression analysis indicated that the most significant CF correlates were SES $(\beta=0.45 ; \mathrm{p}<0.001)$, age $(\beta=$ $-0.12 ; \mathrm{p}<0.001)$, SS $(\beta=0.12 ; \mathrm{p}=0.001)$, GDS $(\beta=-0.11 ; \mathrm{p}=0.003)$ and $\operatorname{QoL}(\beta=0.08 ; \mathrm{p}=0.017)$. The overall regression model explained $36 \%$ of the total variance in the COGTEL. The oldest and the more depressed adults obtained lower scores for FC. The present study suggests that, between the correlates studied, SES was the strongest predictor in the explanation of $\mathrm{CF}$ in older adults.
\end{abstract}

Keywords: Older adults; Cognitive function; Socioeconomic status.

\section{RESUMO}

Os objetivos deste estudo foram: (1) investigar as diferenças associadas à idade na função cognitiva (FC), status nutricional (MNA), atividade física (AF), qualidade de vida (QV), depressão, satisfação social (SS) e estatuto socioeconômico (ESSE), e (2) explorar as relaçôes entre a FCe as varáveis anteriores. Este estudo, de natureza transversal, incluiu 268 homens e 433 mulheres (71,4 \pm 7,0 anos de idade). A FC foi determinada a partir do Cognitive Telephone Screening Instrument (COGTEL) e do Mini-Mental State Examination (MMSE). Os preditores analisados incluíram: o Mini Nutritional Assessment (MNA), a AF (questionário de Baecke modificado para idosos), a $Q V$ (SF-12), a Escala de Depressão em Geriatria (GDS), a Escala de Satisfação com o Suporte Social e o ESSE (Estatuto Socioeconômico). Todos os instrumentos foram aplicados sob forma de entrevista. Um t-teste de medidas independentes identificou scores significativamente mais elevados nos adultos-idosos mais jovens (60 - 69 anos de idade) na $F C(p<0,001), A F(p=0,046)$ e ESSE $(p=0,007)$, comparativamente aos mais idosos (70 91 anos de idade). Os resultados da análise de regressão linear múltipla indicaram que os preditores mais significativos da FC foram: $\operatorname{ESSE}(\beta=0,45 ; p<0,001)$, idade $(\beta=-0,12 ; p<0,001)$, SS $(\beta=0,12 ; p=0,001), G D S(\beta=-0,11 ; p=0,003)$ e $Q V(\beta=0,08 ; p=$ 0,017). O modelo de regressão testado, explicou $36 \%$ da variância total do COGTEL. As pessoas mais idosas e deprimidas obtiveram scores mais baixos na FC. Este estudo sugere que entre os preditores estudados, 0 ESSE é a variável mais forte na explicação da FC nos adultos idosos.

Palavras-chave: Adultos-idosos; Função cognitiva; Estatuto socioeconômico.

\section{$\Theta(\oplus \Theta \Theta$}

Copyright: This is an open-access article distributed under the terms of the Creative Commons Attribution License $^{\circledR}$, which permits unrestricted use, distribution, and reproduction in any medium, provided that the original author and source are credited. 


\section{Introduction}

Successful aging is associated with the level of functioning of several functional areas, such as the sensorial, motor and cognitive areas ${ }^{1}$. The main factors that determine the functionality of individuals are closely related to aspects of a genetic nature and lifestyle ${ }^{2}$ adopted throughout life. The reduction in cognitive function associated with age is frequently associated with loss of independence, institutionalization and decrease in quality of life, in general ${ }^{3}$.

Cognitive function, normally assessed with performance tests, is determined through several subdomains. Short-term verbal memory, long-term verbal memory, work memory, verbal fluency, inductive reasoning and prospective memory are some examples ${ }^{4}$. Among the types of cognitive decline, memory is undoubtedly more associated with aging, as it is considered to be one of the main complaints of older adults ${ }^{5}$. As an example, work memory should be mentioned in particular, required for arithmetic operations and longterm memory, including episodic memory, referring to specific events connected to a certain time and place ${ }^{4,5}$. Verbal fluency/executive function impairments, often associated with changes in the volume and function of the pre-frontal cortex and neurotransmitters, namely dopamine, or even with the decrease in white matter, are linked to motor function decline ${ }^{6}$, low performance in tasks related to immediate memory, long-term memory and information processing speed ${ }^{7}$.

Among the potentially changeable factors, a cognitively-active lifestyle with complex daily tasks, reading or game playing has been shown as a predictor of cognitive performance among older adults ${ }^{8}$. Regular physical activity practice has been recommended as a promising non-pharmacological intervention to prevent cognitive decline associated with age and neuro-degenerative diseases ${ }^{9}$. Additionally, nutrition plays an important role in the development of cognitive decline among older adults, as they are more vulnerable to nutritional deficits. Although the relationship between cognitive function performance and nutritional status is complex and not completely understood, malnutrition is believed to play a key role in the development of cognitive decline ${ }^{10}$.

Limitations associated with cognitive function have a direct effect on health-related quality of life, as the decline of this function results in direct harm to physical, emotional and social functioning ${ }^{3}$. In this context, depression has been considered to be a factor that affects attention, memory, concentration, motivation, learning capacity and decision making and, consequently, it is closely associated with cognitive deficits $^{11}$. On the other hand, social support has been seen as an important protective factor of cognitive function. Thus, good social and emotional support, including regular social contacts, apart from a good relationship among community members, are factors that increase the protection of cognitive function ${ }^{12}$. Finally, better life conditions, namely the offer of a greater number of activities, better medical care, favorable material conditions, available literature tools and educational systems throughout life are associated with better cognitive function performance ${ }^{13,14}$.

Although some studies have identified the factors that most frequently contribute to cognitive function decline, the interactions between cognitive function predictors must be explored more deeply. First of all, the relationships between cognitive function and changeable individual factors are yet under discussion due to their complexity, the use of different assessment instruments, and the diversity of contexts where individuals interact with each other. Second, as far as we know, few studies on these relationships have been conducted in Northern Brazil. In this sense, a more indepth understanding of such interactions can contribute to a better development of intervention strategies, aiming to prevent functional autonomy losses among older adults.

Therefore, the main objectives of the present study were as follows: (1) to investigate the differences associated with age in cognitive function $(\mathrm{CF})$, nutritional status (MNA), physical activity (PA), quality of life (QoL), depression, social satisfaction (SS) and socioeconomic status (SES); and (2) to explore the relationships between cognitive function and the previous variables in a deeper way.

\section{Methods}

Of all 756 older adults who accepted to be evaluated, 56 were excluded for the following reasons: 48 due to co-morbidities that compromised the execution of assessment protocols, six for not completing the tests, one for cognitive deficit, and one for other reasons. Thus, the final sample was comprised of 701 older adults (268 men and 433 women, of which 380 were aged between 60 and 69 years and 321 between 70 and 91 years, with a mean age of 71.4 years $(\mathrm{SD}=7.0)$. This is a group of volunteers with unique geographical and 
cultural characteristics, who were recruited through advertisements for a major study on health, lifestyles and functional fitness. This was advertised in newspapers, churches, elderly support centers and groups or associations of elderly individuals in the cities of Apuí, Fonte Boa and Manaus (Amazonas state, Northern Brazil). Data were collected during 2016. The sample size was determined according to a previous two-tailed power analysis with an alpha probability $=0.05$ and power of 0.98. According to this estimate, the sample size should include 707 participants approximately.

The inclusion criteria were as follows: (1) to live in one of the three previously mentioned geographical areas of Brazil; (2) to be aged at least 60 years; (3) to be able to walk independently to visit local institutions where assessments were performed, and (4) not to have reported health problems that were considered to be absolute contraindications against physical activity practice $^{15}$. The following exclusion criteria were used: low level of physical functionality [assessed with the physical functionality questionnaire ${ }^{16}$, severe cognitive deficits ${ }^{17}$ and co-morbidity that affected the practice of physical activities.

Participants were individually assessed in face-toface interview sessions by field team members, trained for the application of protocols. Each assessment lasted two hours and 30 minutes per participant on average. Aiming to maximize the consistency of assessment procedures, training sessions were performed among field team members and, in a second stage, in a group of older adults. The last stage of the field team preparation coincided with the pilot study with 90 older adults aged between 59 and 85 years, living in the cities of Apuí, Fonte Boa and Manaus. Test-retest reliability of the assessment team was considered to be high $(r \geq 0.70)$.

The assessments were performed in each of the cities associated with the following local institutions: Open University for Senior Citizens at the Amazonas State University; Federal Institute of Education, Science and Technology of the Amazonas State; Referral Center for Social Work; Oscar de Paulo Portela City Library and São Paulo State Social Center for the Elderly.

This research project followed the ethical principles found in Resolution 466/12 of the National Health Council of the Brazilian Ministry of Health and approved by the Human Research Ethics Committee of the Amazonas State University under official opinion number 1.599.258 - CAAE: 56519616.6.0000.5016. This project was also presented to and approved by the
Scientific Committee of the Department of Physical Education and Sports, School of Social Sciences, University of Madeira, Portugal. Participation was voluntary and participants were contacted directly by the team of investigators responsible for the study and thus recruited. All participants signed an informed consent form.

The Cognitive Telephone Screening Instrument (COGTEL) is comprised of six sub-tests including important cognitive function domains: (1) prospective memory; (2) short-term verbal memory; (3) work memory; (4) inductive reasoning; (5) verbal fluency, and (6) long-term verbal memory. A COGTEL total score (continuous scale) was calculated according to the following formula: COGTEL total score $=7.2 *$ prospective memory +1.0 * short-term verbal memory $+0.9 \times$ long-term verbal memory $+0.8 *$ work memory $+0.2 *$ verbal fluency $+1.7 *$ inductive reasoning. All procedures related to the application of the COGTEL could be consulted in detail in a previous publication from the author of this instrument ${ }^{4}$. The COGTEL psychometric properties were previously determined in a sample of Brazilian older adults ${ }^{18}$. Test-retest reliability $(0.85 ; \mathrm{p}<0.001)$ and the convergent validity of the MMSE (0.93; $\mathrm{p}<0.001)$ were high.

The assessment of mental state was performed with the Mini Mental State Examination (MMSE) ${ }^{17}$. The MMSE consists of five sub-sections that include orientation (0-10 points), immediate and short-term memory (0-3 points each), attention and concentration (0-5 points), language and constructive ability (0-9 points). The total score (0-30 points), derived from the sum of scores of the five sub-sections, was used in the present study.

The nutritional assessment was performed with the Mini Nutritional Assessment (MNA) ${ }^{19}$. The MNA score is obtained from the total sum of 18 questions comprising this questionnaire (with a maximum of 30 points).

Physical activity assessment was performed with the Baecke Questionnaire adapted for older adults ${ }^{20}$. This questionnaire is based on the last 12 months and it is divided into three sections: (1) household tasks/ activities; (2) sports activities (only regular activities that last at least one hour per week), and (3) free time activities. All activities were categorized according to posture (sitting or standing) and body movement (standing, walking, cycling, swimming). The equations used to calculate the scores of the three sections and the psychometric properties of the instrument can be consulted in Voorrips et al. ${ }^{20}$. In this study, only a total 
score of physical activity was used, calculated from the mean scores of the three sections.

The Geriatric Depression Scale (GDS) ${ }^{21}$ is one of the instruments most frequently used to identify depression in older adults. The short version is comprised of 15 close-ended questions (yes or no). The total score was used in the present study.

The assessment of perception of health-related quality of life was based in the original version of the MOS SF-36 questionnaire (Medical Outcomes Study 36-item Short-Form Health Survey). In the present study, the short-version of the SF-122 ${ }^{22}$ was used. Like the SF-36, the domains or dimensions of the SF-12 are grouped into two components: physical component and mental component. In this study, only the total score of the SF-12 was taken into consideration (physical component + mental component).

The Social Support Satisfaction Scale ${ }^{23}$ is comprised of 15 items, each with a score ranging from one to five points. These 15 items are distributed into four dimensions or factors: 1) satisfaction with friends - it measures one's satisfaction with one's friendships/friends; 2) intimacy - it measures the perception of existence of intimate social support; 3 ) satisfaction with the family - it measures one's satisfaction with the existing family social support; 4) social activities - social activities performed. The score for the total scale can vary between 15 and 75 points, where the highest score corresponds to a higher perception of social support.

Socioeconomic status was assessed with the questionnaire developed by the Associação Brasileira de Empresas de Pesquisa (ABEP - Brazilian Association of Market Research Institute) $)^{24}$. To achieve this, participants were asked about ownership and the number of the following items: 1) color TVs; 2) radio; 3) bathrooms; 4) automobiles; 5) housemaid; 6) vacuum cleaners; 7) washing machine; 8) DVD and/or VCR player; and 9) refrigerator/freezer (an independent unit or part of a duplex refrigerator). The second part of the questionnaire includes questions about level of education (indicating the total time in school years). The following scores were taken into consideration: $0=$ Illiterate/incomplete primary education (grades 1 to 4 ); 1 = complete primary education (grades 1 to 4 )/incomplete primary education (grades 5 to 8 ); 2 = Complete primary education (grades 5 to 8)/incomplete secondary education; 3 = Complete secondary education/incomplete higher education; 4 = Complete higher education. The sum of the two parts of the questionnaire was con- sidered in the final calculation of socioeconomic status, leading to the overall score. The descriptive characteristics of participants were detailed through means and standard deviation. All data were tested for normality with the Kolmogorov-Smirnov test.

First of all, a t-test of independent measures was performed to compare the cognitive function, nutritional status, physical activity, quality of life, depression, social satisfaction and SES among young-old adults (60-69 years of age) and old-old adults (70-91 years of age). Next, bivariate correlations were used to explore the relationship between cognitive function variables (COGTEL and MMSE) and the previously mentioned behavioral, psychological and social variables, using Pearson's correlations.

Finally, a multiple linear regression analysis was conducted to quantify the independent contribution of each of the predictive variables for cognitive function (assessed through the COGTEL and MMSE). Betas were determined to assess the relative independent contributions of each predicting variable and the $\mathrm{r}^{2}$ adjusted to calculate the percentage of variance explained in the COGTEL and MMSE scores. Preliminary analyses were performed to guarantee that the main statistical assumptions were not violated. The significance level was established at $\mathrm{p}<0.05$. The analysis was performed with the SPSS statistical software, version 23.0.

\section{Results}

A t-test of independent measures identified differences with a statistical significance between age groups, favoring the group of young-old adults for COGTEL $($ Mean $=20.4 ;$ Standard deviation $=9.6$, and Mean = 17.3; Standard deviation $=9.0, \mathrm{p}<0.001)$ and MMSE scores $($ Mean $=25.0 ;$ Standard deviation $=4.0$; and Mean $=23.7 ;$ Standard deviation $=4.4 ; \mathrm{p}<0.001)$. Young-old adults (60-69 years) also showed significantly higher scores for physical activity $(\mathrm{p}=0.046)$ and SES $(p=0.007)$, when compared to old-old adults (Table 1$)$.

Pearson correlations between cognitive function and behavioral, psychological and social variables are shown in Table 2 . There is a partially negative correlation between COGTEL ( $r=-0.36, p<0.001)$, MMSE $(\mathrm{r}=-0.39, \mathrm{p}<0.001)$ and the Geriatric Depression Scale score, thus suggesting that high scores of depression are associated with low performances in cognitive function tests. On the other hand, a significantly positive correlation was found between COGTEL, MMSE and nutritional status $(0.100 \geq \mathrm{r} \leq 0.112 ; \mathrm{p}<$ 
$0.05)$, physical activity $(0.187 \geq \mathrm{r} \leq 0.193 ; \mathrm{p}<0.001)$, quality of life $(0.241 \geq \mathrm{r} \leq 0.252 ; \mathrm{p}<0.001)$, social satisfaction $(0.265 \geq r \leq 0.289 ; \mathrm{p}<0.001)$ and SES $(0.425$ $\geq \mathrm{r} \leq 0.547 ; \mathrm{p}<0.001)$.

Table 1 - Differences between cognitive function means of behavioral, psychological and social variables according to age.

\begin{tabular}{lccc}
\hline & $60-69$ years & $70-91$ years & \\
\cline { 2 - 3 } & Mean $\pm \mathrm{SD}$ & Mean $\pm \mathrm{SD}$ & $\mathrm{p}$ \\
\cline { 2 - 3 } & $\mathrm{n}=380$ & $\mathrm{n}=321$ & \\
\hline COGTEL & $20.0 \pm 9.6$ & $17.3 \pm 9.0$ & $<0.001$ \\
MMSE & $25.0 \pm 4.0$ & $23.7 \pm 4.4$ & $<0.001$ \\
MNA & $26.7 \pm 2.4$ & $26.7 \pm 2.3$ & 0.971 \\
PA- total & $7.2 \pm 3.6$ & $6.6 \pm 3.6$ & 0.046 \\
GDS & $8.3 \pm 2.2$ & $8.6 \pm 2.4$ & 0.056 \\
HRQoL SF12 & $39.2 \pm 6.4$ & $38.6 \pm 7.1$ & 0.189 \\
Social satisfaction & $31.3 \pm 8.2$ & $30.4 \pm 7.2$ & 0.136 \\
SES & $12.5 \pm 4.3$ & $11.6 \pm 4.2$ & 0.007 \\
\hline
\end{tabular}

COGTEL: Cognitive Telephone Screening Instrument; MMSE: Mini-Mental State Examination; MNA: Mini Nutritional Assessment; PA: physical activity; GDS: geriatric depression scale; HRQoL (SF12): health-related quality of life; SES: socioeconomic status.

Table 2 - Pearson correlations between cognitive function and behavioral, psychological and social variables.

\begin{tabular}{lcc}
\hline & COGTEL & MMSE \\
\hline MNA & $0.112^{*}$ & $0.100^{*}$ \\
PA - total & $0.193^{* *}$ & $0.187^{* *}$ \\
GDS & $-0.355^{* *}$ & $-0.385^{* *}$ \\
HRQoL SF12 & $0.252^{* *}$ & $0.241^{* *}$ \\
Social satisfaction & $0.289^{* *}$ & $0.265^{* *}$ \\
SES & $0.547^{* *}$ & $0.425^{* *}$ \\
\hline
\end{tabular}

${ }^{*} \mathrm{p}<0.005 ;{ }^{*} \mathrm{p}<.001$; COGTEL: Cognitive Telephone Screening Instrument; MMSE: Mini-Mental State Examination; MNA: Mini Nutritional Assessment; PA: physical activity; GDS: geriatric depression scale; HRQoL (SF12): health-related quality of life; SES: socioeconomic status.

The contributions of nutritional status, physical activity, quality of life, depression, social satisfaction and SES to the explanation of cognitive function variation were investigated in the multiple linear regression analysis (Table 3). The most significant predictors of cognitive function (COGTEL) were the SES ( $\beta=0.45 ; p<$ $0.001)$, age $(\beta=-0.12 ; \mathrm{p}<0.001)$, social satisfaction $(\beta$ $=0.12 ; p=0.001)$, depression $(\beta=-0.11 ; \mathrm{p}=0.003)$ and quality of life $(\beta=0.08 ; p=0.017)$. The regression model tested explained $36 \%$ of the total variance of COGTEL.

\section{Discussion}

In the present study, old-old adults showed significantly lower mean values of cognitive function (asses-
Table 3 - Multiple linear regression between cognitive function and their behavioral, psychological and social predictors.

\begin{tabular}{|c|c|c|c|c|}
\hline & $\begin{array}{c}\text { Adjusted } \mathrm{B} \pm \\
\mathrm{SE}\end{array}$ & Beta & $\mathrm{p}$ & $95 \% \mathrm{IC}^{*}$ \\
\hline \multicolumn{5}{|c|}{$\operatorname{COGTEL~}\left(\mathrm{R}_{\mathrm{adj}}^{2}=0.355\right)$} \\
\hline Age (years) & $-0.161 \pm 0.042$ & -0.117 & $<0.001$ & $-0.244 ;-0.077$ \\
\hline MNA & $0.021 \pm 0.130$ & 0.005 & 0.872 & $-0.235 ; 0.277$ \\
\hline PA - total & $-0.005 \pm 0.085$ & -0.002 & 0.957 & $-0.172 ; 0.163$ \\
\hline HRQoL SF12 & $0.231 \pm 0.096$ & 0.082 & 0.017 & $0.042 ; 0.420$ \\
\hline GDS & $-0.469 \pm 0.155$ & -0.113 & 0.003 & $-0.773 ;-0.165$ \\
\hline Social satisfaction & $0.140 \pm 0.042$ & 0.115 & 0.001 & $0.057 ; 0.222$ \\
\hline SES & $0.984 \pm 0.074$ & 0.446 & $<0.001$ & $0.839 ; 1.130$ \\
\hline \multicolumn{5}{|l|}{$\operatorname{MMSE}\left(\mathrm{R}_{\mathrm{adj}}^{2}=0.267\right)$} \\
\hline Age (years) & $-0.082 \pm 0.020$ & -0.134 & $<0.001$ & $-0.122 ;-0.042$ \\
\hline MNA & $-0.026 \pm 0.062$ & -0.014 & 0.674 & $-0.148 ; 0.096$ \\
\hline $\mathrm{PA}$ - total & $0.013 \pm 0.041$ & 0.011 & 0.748 & $-0.067 ; 0.093$ \\
\hline HRQoL SF12 & $0.094 \pm 0.046$ & 0.074 & 0.042 & $0.003 ; 0.184$ \\
\hline GDS & $-0.390 \pm 0.074$ & -0.210 & $<0.001$ & $-0.535 ;-0.245$ \\
\hline Social satisfaction & $0.043 \pm 0.020$ & 0.080 & 0.030 & $0.004 ; 0.083$ \\
\hline SES & $0.295 \pm 0.035$ & 0.299 & $<0.001$ & $0.226 ; 0.364$ \\
\hline
\end{tabular}

COGTEL, Cognitive Telephone Screening Instrument; MMSE, Mini-Mental State Examination; MNA, Mini Nutritional Assessment; PA, physical activity; GDS, geriatric depression scale; HRQoL (SF12), health-related quality of life; SES, socioeconomic status.

sed with COGTEL and MMSE) in the total score of physical activity and SES, when compared to young-old adults. There was a negative correlation between cognitive function and the total score of the Geriatric Depression Scale. On the other hand, a positive correlation was found between cognitive function and nutritional status, physical activity, quality of life, social satisfaction and SES. Among the predictors studied, SES was the strongest variable to explain cognitive function, followed by social satisfaction and age.

The differences in means of cognitive function between young-old adults and old-old adults found in the present study are supported by the theory that there are structural and functional changes in the brain associated with aging and directly connected to cognitive function changes. These changes appear due to modifications to neuronal membranes, metabolism and cell death in the brain caused by oxidative stress and the reduction in one's capacity to remove free radicals $^{25}$, due to the decline in mitochondrial function and accumulation of harmful proteins ${ }^{26}$.

Similarly, the differences found in the total score of physical activity are justified by the loss of functional ca- 
pacity in several dimensions of functional fitness (resistance, strength, flexibility and balance $)^{17}$. In addition to the reduction in functional fitness, other changes associated with aging in several physiological systems (cardiopulmonary, musculoskeletal, nervous and immunological) ${ }^{17,27}$ can decrease the level of daily physical activity.

Currently, although Brazil faces a difficult period of socioeconomic and political crisis, older adults have greater access to assets, services and products, compared to the previous decades. In contrast, as a reflection of socioeconomic improvement, in half a century (19602010), life expectancy in Brazil increased by 25.4 years, from 48.0 to the current 73.4 years $^{28}$. In terms of Educational Systems, the Brazilian government has also developed certain strategies, such as the availability of evening courses for adults and older adults, learning workshops, and open universities for older adults, aiming to increase the educational level of the population ${ }^{14}$. These indicators can help to justify the fact that higher scores for socioeconomic status were found in youngold adults, compared to those born a decade earlier.

The second objective of the present study was to explore the interactions between cognitive function and behavioral, psychological and social variables. First of all, it should be emphasized that there was a negative correlation between cognitive function tests and the total score of the Geriatric Depression Scale, thus suggesting that high scores of depression are associated with low performance in cognitive function tests. Previous studies have shown that depression can affect attention, memory, concentration, motivation, learning capacity and decision-making and it can even cause cognitive deficits ${ }^{11}$. Thus, there seems to be a consensus in the literature about the existence of an inverse relationship between depression and cognitive performance ${ }^{11,12}$. Second of all, the results of the present study corroborate the evidence that better cognitive function is associated with better nutritional status ${ }^{10}$, a higher level of physical activity ${ }^{9}$, a better self-perception of health-related quality of life $^{3}$, a higher level of social satisfaction $^{29,12}$ and a higher socioeconomic level ${ }^{30,13}$.

Evidence of cognitive decline is associated with very sensitive areas such as memory, executive function, language, gnosis/perception and visual-spatial function, which determine independence, quality of life and the strength of relationships between multiple variables taken into consideration in the present study. They can be a reference for the definition of more efficient intervention strategies focused on the improve- ment of cognitive function in older adults.

Finally, the results of the regression analysis indicate that the most significant contributions to the explanation of variance in the cognitive function score were as follows: SES (45\%), satisfaction with social support (12\%), chronological age (12\%) depression (11\%) and quality of life (8\%). This means that, when planning activities to develop cognitive function, age must not be the only discriminating factor for interventions in older adults. This suggests that, regardless of one's chronological age, other variables must also be taken into consideration, especially those associated with social and psychological aspects (i.e. depressed older adults). On the other hand, as the socioeconomic level is the strongest variable to explain cognitive function, adapting intervention programs to different socioeconomic levels could be more important and profitable. In this domain, the contribution of the level of education to this variable should be emphasized, as it can play a key role in the adequacy of such interventions. Moreover, the level of education has been used to assess the simultaneous validity of instruments of cognitive function assessment ${ }^{4}$.

The conclusions of the present study must consider the following two limiting factors: the sample characteristics and the study design. Although the present study has a reasonable sample size, the use of sampling procedures through media advertisements (passive recruiting) and personal contacts (active recruiting) conditions study participant characteristics (i.e. privileged participation of healthier older adults). Additionally, we understand that the cross-sectional design of this study limits the conclusions about the direction of relationships between variables correlated with cognitive function, i.e. it is not possible to establish a cause-effect relationship. However, this study is of great importance, as it identifies potentially changeable variables correlated with cognitive function. A future investigation is required, especially aimed at factors that influence the strength of relationships between the variables studied (with an emphasis on level of education) and for the assessment of the effect of intervention programs on the community, focused on prevention and early diagnosis of cognitive decline and promotion of cognitive capacity in older adults.

In conclusion, the results of the present study suggest that the implementation of intervention programs focused on the improvement of cognitive function in older adults must be sufficiently broad to consider not only the chronological age, but also other predictors of cognitive 
function, such as social aspects (socioeconomic level and satisfaction with social support), psychological aspects (depression) and health-related quality of life.

\section{Conflicts of interest}

The authors declare no conflict of interest.

\section{Author contributions}

Tinôco MA, responsible for the literature search, writing, and data collection; Gouveia ÉR, participated in the initial study conception, writing, critical review of the content and final approval of the version to be published; Ihle A, contributed to the formulation of the research question, data analysis and interpretation; Kliegel M, participated in the initial study conception, made the COGTEL instrument available for cognitive function assessment; Jurema J, participated in the initial study conception and approval in the Research Ethics Committee and supervision of data collection; Machado FT, Odim AP and Muniz BR, participated in the data collection and contributed to the formulation of the research question; Ribeiro EE, contributed to the formulation of the research question and text writing; Gouveia BR, contributed to the formulation of the research question and text writing; Freitas DL, significantly contributed to the study conception and design, supervised data collection and helped with text writing.

\section{Acknowledgements}

Authors would like to thank all team members for the technical support during data collection. We are especially thankful for all volunteer participants who accepted to be included in the sample.

\section{References}

1. Rowe JW, Kahn RL. Successful aging. Gerontologist. 1997;37(4):433-40.

2. Zhao E, Tranovich MJ, Wright VJ. The role of mobility as a protective factor of cognitive functioning in aging adults: a review. Sports Health. 2014;6(1):63-9.

3. Ribeiro PCC, Yassuda M. Cognição, estilo de vida e qualidade de vida na velhice. In: Neri AL. (ed). Qualidade de vida na velhice: enfoque multidiciplinar. Campinas: Atheneu; 2007. p. 189-209.

4. Kliegel M, Martin M,Jager T. Development and validation of the Cognitive Telephone Screening Instrument (COGTEL) for the assessment of cognitive function across adulthood. J Psychol. 2007;141(2):147-70.

5. J. Psicologia do envelhecimento e do idoso. 4. ed. Porto: Livpsic; 2010.

6. Andrews-Hanna J, Snyder A, Vincent J, Lusting C, Head D, Raichle $\mathrm{M}$, et al. Disruption of large-scale brain systems in advanced aging. Neuron. 2007;56(5):924-35.

7. Gunning-Dixon F, Raz N. The cognitive correlates of white matter abnormalities in normal aging: a quantitative review. Neuropsychology. 2000;14(2):224-32.

8. Wang H, Karp A, Winblad B, Fratiglioni L. Late-Life engagement in social and leisure activities is associated with a decreased risk of dementia: a longitudinal study from the Kungsholmen Project. Am J Epidemiol. 2002;155(12):1081-87.
9. Covel G, Hoffman-Snyder C, Wellik K, Woodruff B, Geda Y, Caselli R, et al. Physical activity level and future risk of mild cognitive impairment or dementia: a critically appraised topic. Neurologist. 2015;19(3):89-91.

10. Malara A, Sgrò G, Caruso C, Ceravolo F, Curinga G, Renda $\mathrm{GF}$, et al. Relationship between cognitive impairment and nutritional assessment on functional status in Calabrian long-term-care. Clin Interv Aging. 2014;9:105-10.

11. Gallo JJ, Rebok GW, Tennstedt S, Wadley EG, Horgas A. The Advanced Cognitive Training for Independent and Vital Elderly (Active) Study Investigators. Aging Ment Health. 2003;7(6):469-80.

12. Fratiglioni L, Wang HX, Ericsson K, Maytan M, Winblad B. Influence of social network on occurrence of dementia: a community-based longitudinal study. Lancet. 2000;355(9212):1315-9.

13. Wee LE, Yeo WX, Yang GR, Hannan N, Lim K, Chua C, et al. Individual and area level socieconomic status and its association with cognitive function and impairment (Low MMSE) among community-dwelling elderly in Singapore. Dement Geriatr Cogn Dis Extra. 2012;2(1):529-42.

14. Krug R, Ono L, Quialheiro A, d'Orsi E, Ramos L, Xavier A. A Stimulation and rehabilitation program: Oficina da Lembrança. Rev Bras Ativ Fís Saúde. 2015;20(5):534-40.

15. American College of Sports Medicine. ACSM's guidelines for exercise testing and prescription. 9nd ed. Philadelphia: Lippincott Williams \& Wilkins; 2014.

16. Rikli RE, Jones CJ. Senior fitness test manual. 2nd ed. Champaign, IL: Human Kinetics Publishers Inc; 2013.

17. Folstein M, Folstein SE, Mchugh PR. Mini-mental state: A practical method for grading the cognitive state of patients for the clinician. J Psychiatr Res. 1975;12(39):189-98.

18. Ihle, A, Gouveia, ÉR, Gouveia, BR, Kliegel, M. The Cognitive Telephone Screening Instrument (COGTEL): A brief, reliable, and valid tool for capturing interindividual differences in cognitive functioning in epidemiological and aging studies. Dement Geriatr Cogn Disord Extra. 2017;7(3):339-45.

19. Rubenstein LZ, Karker JO, Salva A, Guigoz Y, Vellas B. Screening for undernutrition in geriatric practice: developing the short-form Mini Nutritional Assessment (MNA-SF). J Ger Med Sci. 2001;56(6):366-72.

20. Voorrips LE, Ravelli AC, Dongelmans PC, Deurenberg P, Van Staveren W. A physical activity questionnaire for the elderly. Med Sci Sports Exerc. 1999;23(8):974-9.

21. Yesavage JA, Brink TL, Rose TL, Lum O, Huang V, Adey $\mathrm{M}$, et al. Development and validation of geriatric depression scale. J Psychiatr Res. 1983;17(1):37-49.

22. Ribeiro JLP. O importante é a saúde: estudo de adaptação de uma técnica de avaliação do estado de saúde - SF - 36. Lisboa: Merck Sharp \& Dolme; 2005.

23. Ribeiro JLP. Escala de Satisfação com o Suporte Social (ESSS). Análise Psicológica. 1999; 3(XVII):547-58.

24. Associação Brasileira de Empresas de Pesquisa (ABEP). Critério de classificação econômica Brasil. 2018. Disponível em: http://www.abep.org.

25. Poon H, Calabrese V, Scapagnini G, Butterfield D. Free radicals: key to brain aging and heme oxygenase as a cellular response to oxidative stress. J Gerontol A Biol Sci Med Sci. 2004;59(5):478-93.

26. Hipkiss A. Accumulation of altered proteins and ageing: causes and effects. Exp Gerontol. 2006;41(5):464-73. 
27. Gouveia ÉR, Maia JA, Beunen GP, Blimkie CJ, Fena EM, Freitas DL. Functional fitness and physical activity of Portugueses community-residing older adults. J Aging Phys Act. 2013;21(1):1-19.

28. Instituto Brasileiro de Geografia e Estatística (IBGE). Dados do Censo Demográfico. 2010. Disponível em: http:// censo2010.ibge.gov. br/dados_divulgados/index.php?uf=31. Acesso em: 14 fev. 2017.

29. Grenn A, Rebok G, Lyketsos C. Influence of social network characteristics on cognitive and functional status aging. Int J Geriatr Psychiatry. 2008;23(9):972-8.
30. Xu X, Liang J, Bennett JM, Botoseneanu A, Allore HG. Socioeconomic and Multidimensional Health trajectories: Evidence of Convergence in Later Old Age. J Gerontol B Psychol Sci Soc Sci. 2014;70(4):661-71.

Recebido: 20/12/2017

Aprovado: 30/05/2018

\section{Quote this article as:}

Tinôco MA, Gouveia ÉR, Ihle A, Kliegel M, Jurema J, Machado FT, et al. Cognitive function associations in older adults from the Amazonas state, Brazil. Rev Bras Ati Fis Saúde. 2018;23:e0013. DOI: 10.12820/rbafs.23e0013 